\title{
Variations of culture parameters in a pilot-scale thin-layer reactor and their influence on the performance of Scenedesmus almeriensis culture
}

\author{
M. Barceló-Villalobos ${ }^{\mathrm{a}, *}$, C. Gómez Serrano ${ }^{\mathrm{b}}$, A. Sánchez Zurano ${ }^{\mathrm{b}}$, L. Alameda García ${ }^{\mathrm{b}}$, \\ S. Esteve Maldonado ${ }^{c}, J_{\text {. Peña }}{ }^{\mathrm{b}}$, F.G. Acién Fernández ${ }^{\mathrm{b}}$ \\ ${ }^{a}$ Department of Informatics, Universidad de Almería, E04120 Almería, Spain \\ ${ }^{\mathrm{b}}$ Department of Chemical Engineering, Universidad de Almería, E04120 Almería, Spain \\ ' IES AZCONA, Calle Policía José Rueda Alcaraz, 1, 04006 Almería, Spain
}

\section{A R T I C L E I N F O}

\section{Keywords:}

Thin-layer cascade

Photosynthesis

Irradiance

Gradients

Temperature

Dissolved oxygen

\begin{abstract}
A B S T R A C T
The variations in culture conditions (irradiance, temperature, $\mathrm{pH}$ and dissolved oxygen) in a thin-layer $120 \mathrm{~m}^{2}$ surface reactor have been studied, both in terms of position inside the reactor and time of the daylight cycle. Results demonstrate that average irradiance and temperature to which the cells are exposed are mainly a function of time, whereas $\mathrm{pH}$ and dissolved oxygen concentrations also showed relevant gradients depending on their position inside the reactor. The existence of gradients has been demonstrated to reduce the culture performance, using both chlorophyll-fluorescence and net photosynthesis rate methods. Moreover, the influence of culture conditions on Scenedesmus almeriensis cell performance was modelled. The obtained model allows us to quantify the loss in productivity caused by inadequate culture conditions; the net photosynthesis rate being demonstrated as only $32 \%$ of the maximal achievable. This is the first step in optimizing and scaling-up this type of reactor for industrial applications.
\end{abstract}

\section{Introduction}

There is always a requirement for large-scale microalgae biomass production to increase the biomass productivity of outdoor cultures and to approximate it to the maximum theoretical values. To do so, three major issues have to be solved: (i) to produce robust strains capable of rapid growth and of producing large amounts of biomass under a wide range of culture conditions, (ii) to use photobioreactors capable of providing the optimal conditions required by the selected microalgae strain, and (iii) to be able to adjust the overall production system operation to the changing environmental conditions prevailing in the actual outdoor cultures, both on an hourly and seasonal basis. The production of different microalgae strains in raceway and tubular photobioreactors has been widely reported; these technologies now being the most extended worldwide for microalgae biomass production, both in low-value and high-value applications, respectively (Benemann, 2013; Grobbelaar, 2010). In the case of thin-layer reactors, their use still remains at the laboratory or pilot scale, no industrial facilities with this technology exists as yet in spite of the high productivity already reported when using these types of photobioreactors (Acién et al., 2017).

Thin-layer reactors have been developed for decades at the laboratory of photosynthesis in Trebon, Czech Republic (Masojídek and Prášil, 2010). These reactors are characterized by their low-depth culture, which is recirculated over a flat surface by providing it with an adequate slope of 0.1 to $2 \%$. Under these conditions, the culture depth ranges from 5 to $0.5 \mathrm{~cm}$, and biomass concentration values of up to $40 \mathrm{~g} / \mathrm{L}$ can be achieved (Masojídek et al., 2015). This technology has been proposed as one of the most efficient in terms of areal productivity, with values ranging from 30 to $50 \mathrm{~g} / \mathrm{m}^{2}$ day (Masojídek et al., 2015; Morales-Amaral et al., 2015a). The largest reactor of this type was recently built and put into operation in Portugal, having a total surface area of $1500 \mathrm{~m}^{2}$; to date, no figures for this reactor are available. Data from small pilot-scale reactors, of up to $50 \mathrm{~m}^{2}$, show that they have certain problems related to an inadequate mass transfer capacity and the existence of $\mathrm{pH}$ and temperature gradients, along with a significant accumulation of oxygen in the culture, reaching values of up to $400 \%$ Sat (Lívanský et al., 2006; Morales-Amaral et al., 2015b).

To properly optimize microalgae production in these reactors, the first step is to characterize it and then determine how the culture conditions change along the reactor length due to daily variations in environmental conditions (i.e. light and temperature). It has been widely reported that biomass productivity is influenced by temperature and $\mathrm{pH}$, as well as by dissolved oxygen. The effect of temperature is

\footnotetext{
* Corresponding author.

E-mail address: mbv001@ual.es (M. Barceló-Villalobos).
} 

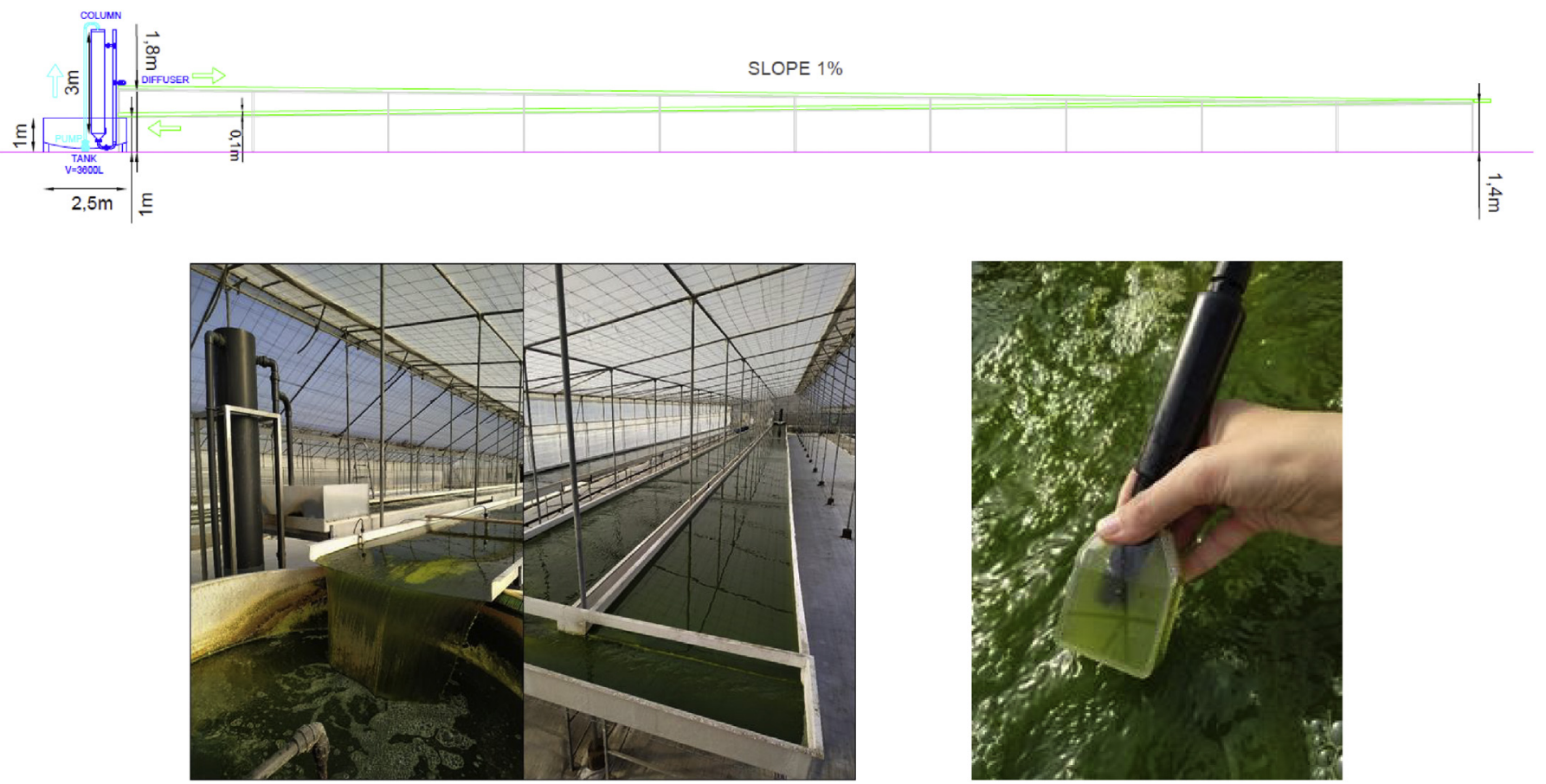

Fig. 1. Scheme of the thin-layer cascade reactor located at the IFAPA Experimental Station (Almería, Spain) (Up). Images of reactor (below-left) and the plastic chamber used to determine the net photosynthesis rate at the different positions (below-right).

analogous to any microorganism, while inadequate $\mathrm{pH}$ also reduces microalgae culture performance. Dissolved oxygen content is also a critical parameter in microalgae production; it is well known that it causes inhibition at concentrations above $250 \%$ Sat. (Camacho Rubio et al., 1999; de Godos et al., 2014; Mendoza et al., 2013). These effects have been previously reported in both tubular and raceway reactors, allowing us to identify the major bottlenecks for each of these reactor types; and consequently the best strategies to resolve them (de Godos et al., 2014; Ippoliti et al., 2016b; Mendoza et al., 2013). Conversely, in thin-layer cascades, the available information is far more limited, the major challenges of which still need to be identified and overcome before scaling-up this technology.

To evaluate the performance of whichever type of reactor, the usual method is to focus on overall biomass productivity. However, biomass productivity does not provide information regarding inadequate culture conditions in the different parts of the reactor or about conditions throughout the day; these measurements have to be carried out in distinct parts of the reactor. Moreover, one also needs to establish the performance of cells under these conditions so as to be able to evaluate the losses in productivity resulting from inadequate culture conditions at different reactor locations or at different points over the day. To evaluate cell performance, rapid methods such as in situ fluorescence of chlorophylls are effective although a more robust estimation can be obtained by evaluating the net oxygen production rate under different culture conditions (Malapascua et al., 2014). Data from cultures performance can be used to develop reliable models that are useful for optimizing the design and operation of any reactor type, including thinlayer cascade reactors (Bernard and Rémond, 2012; Costache et al., 2013; Gao et al., 2018; Ippoliti et al., 2016a).

In this paper, we study the existence of gradients for the most relevant culture parameters (temperature, $\mathrm{pH}$ and dissolved oxygen) in thin-layer cascade reactors; both in terms of their location in the reactor and their daily variation based on environmental conditions. Moreover, we evaluated the performance of the microalgae cells under the different conditions using chlorophyll fluorescence and oxygen production rate methods. Accordingly, the existence of adverse conditions in these types of reactors is elucidated, and the losses in productivity are quantified. This study is the first step in optimizing and scaling-up thinlayer reactors for large-scale commercial microalgae production.

\section{Materials and methods}

\subsection{Microorganism and culture conditions}

The microalga strain Scenedesmus almeriensis (CCAP 276/24) was selected for its adaptability and abundant growth in outdoor reactors. The microalga was produced in a thin-layer reactor utilizing Mann \& Myers medium, prepared using fertilizers: $\left(0.14 \mathrm{~g} \cdot \mathrm{L}^{-1} \mathrm{~K}\left(\mathrm{PO}_{4}\right)_{2}\right.$, $0.18 \mathrm{~g} \cdot \mathrm{L}^{-1} \mathrm{Mg}\left(\mathrm{SO}_{4}\right)_{2}, \quad 0.9 \mathrm{~g} \cdot \mathrm{L}^{-1} \quad \mathrm{NaNO}_{3}, \quad 0.02 \mathrm{~mL} \cdot \mathrm{L}^{-1}$ Welgro, and $0.02 \mathrm{~g} \cdot \mathrm{L}^{-1}$ Kalentol) (Fernández et al., 2012). The inoculum for the reactor was produced in a tubular photobioreactor $\left(3 \mathrm{~m}^{3}\right)$ using the same culture medium. Tubular reactor was operated at a constant $\mathrm{pH}$ of 8 by the on-demand injection of $\mathrm{CO}_{2}$, whereas temperature was controlled by passing cool water by an internal heat exchanger located into the bubble column of this tubular photobioreactor. Dissolved oxygen accumulation over $250 \%$ Sat. was avoided in the tubular photobioreactor by supplying air to the bubble column for oxygen desorption. On this way the culture was maintained below the critical values for this strain (temperature below $40{ }^{\circ} \mathrm{C}$, dissolved oxygen below $250 \%$ Sat. (100\%Sat. is equivalent to $9 \mathrm{mg} / \mathrm{L})$ ).

\subsection{Thin-layer reactor design and operating conditions}

The thin-layer reactor is located at the "IFAPA" Research Centre, (Almería, Spain). The reactor consists of two sloped cultivation plates, each $40 \mathrm{~m}$ long and $1.5 \mathrm{~m}$ wide, connected by a flat channel that acts as a solar collector. The culture is recirculated through this solar collector by a pump after passing through a bubble column for $\mathrm{pH}$ adjustment and oxygen desorption (Fig. 1)). The total surface area of the solar collector reactor is $120 \mathrm{~m}^{2}$ with a water depth of $0.02 \mathrm{~m}$; thus the total culture volume in this section is $2.4 \mathrm{~m}^{3}$. The sump from which the culture is recirculated has a culture volume of $0.7 \mathrm{~m}^{3}$ whereas the bubble column has a volume of $0.3 \mathrm{~m}^{3}$, making the total culture volume $3.4 \mathrm{~m}^{3}$. The reactor is operated in continuous mode by harvesting up to 
$1.0 \mathrm{~m}^{3} /$ day of culture, replacing it with fresh medium prepared using freshwater and fertilizers; therefore, the imposed dilution rate is 0.3 day $^{-1}$. Water evaporation from the reactor is compensated for by the daily addition of water. The culture's $\mathrm{pH}$ is controlled by the ondemand injection of $\mathrm{CO}_{2}$ into the bubble column; alternatively, air is injected to remove oxygen and avoid dissolved oxygen accumulation. The gas flow rate of both $\mathrm{CO}_{2}$ and air entering the bubble column is measured using mass flow meters (PFM 725S-F01-F, SMC, Tokyo, Japan). Air is supplied to the reactor via a blower providing $350 \mathrm{mbar}$ overpressure through a fine bubble diffuser AFT2100 (ECOTEC, Spain) capable of creating bubbles with a diameter of less than $2 \mathrm{~mm}$ at the minimum pressure drop. The culture's temperature was not controlled.

\subsection{In situ measurements in the reactor}

The existence of culture condition gradients was studied by measuring the $\mathrm{pH}$, temperature and dissolved oxygen in the culture at nine different points along the reactor's length, using appropriate temperature, $\mathrm{pH}$ and dissolved oxygen probes (HI98198, Hanna, Spain). Measurements were carried out at different times during the daylight period to determine the variation in existing gradients throughout the day. To analyse the influence of the culture conditions existing at each reactor position on the culture's performance, the net photosynthesis rate at each position was also measured. To do this, culture samples were directly taken from the reactor at the different positions and introduced into a $40 \mathrm{~mL}$ plastic chamber $(0.02 \mathrm{~m}$ in depth), measuring the dissolved oxygen accumulation in this chamber over a period of $5 \mathrm{~min}$ on which maximum accumulation of $20 \%$ sat was measured (Fig. 1).

\subsection{Offline measurements in the laboratory}

In addition to the in situ measurements, the influence of culture conditions on culture performance was determined offline in the laboratory, using the culture conditions $(\mathrm{pH}$, temperature, dissolved oxygen and irradiance) previously found in the reactor at the different positions and times. Thus, it was possible to compare both the in situ experimental measurements and those determined in the laboratory under controlled conditions. Two methods were employed to evaluate the influence of culture conditions on cell performance; the first based on the net photosynthesis rate measurements while the second involved chlorophyll-fluorescence measurements. Both are rapid methods allowing us to evaluate the culture performance in a short time. Additionally, to modelize the net photosynthesis rate response to changes in culture conditions, a set of experiments was performed under laboratory conditions over a wide range of $\mathrm{pH}$ (from 3 to 11), temperature (from 8 to 46), dissolved oxygen (from 0 to $400 \%$ Sat.) and irradiance (from 100 to $2500 \mu \mathrm{E} \mathrm{m}^{-2} \mathrm{~s}^{-1}$ ).

\subsubsection{Net photosynthesis rate measurements}

The net photosynthesis rate was measured using specially-built photo-respirometer equipment. This equipment measures the variation in dissolved oxygen in microalgae samples under controlled conditions. The samples were placed in a stirred cylindrical glass chamber, $60 \mathrm{~mL}$ in volume and $2 \mathrm{~cm}$ in diameter, illuminated using two sets of LED lamps placed to the right and left of the glass chamber. The lamps' intensity was automatically regulated to obtain the desired irradiance inside the chamber once the sample was added. The photo-respirometer was also equipped with sensors for irradiance (ULM 500, Walz, Germany), temperature (PT1000, Crison, Spain), pH (Crison 5343, Spain) and dissolved oxygen (Crison 5002, Spain) located inside the cylindrical glass chamber; to be exact, the irradiance sensor was positioned in the centre of the glass chamber whereas the other sensors were located close to the surface to avoid shadows inside the system.

To determine the photosynthesis rate, samples from the thin-layer cascade were taken and then placed inside the stirred cylindrical glass chamber. Each sample was exposed to three-minute light periods to measure and register the variation in dissolved oxygen under all the conditions. The photosynthesis rate was calculated from the slope of dissolved oxygen accumulation during the light periods. The variations in dissolved oxygen were evaluated in the $70-140 \%$ Sat range, for which the oxygen mass transfer was confirmed to be negligible. Irradiance was modified by adjusting the power of the LED lamps whereas the $\mathrm{pH}$ was modified by adding $\mathrm{HCl}$ or $\mathrm{NaOH}$ to achieve the desired values. The temperature was modified by heating/cooling the samples, whereas the dissolved oxygen concentration was modified by bubbling pure $\mathrm{N}_{2} / \mathrm{O}_{2}$ gases.

\subsubsection{Chlorophyll-fluorescence measurements}

A Pulse-Amplitude-Modulation fluorometer device was utilized (Junior PAM, Walz, Effeltrich, Germany) to estimate the photosynthetic activity of the microalgae cells using the Rapid Light Curves of Electron Transport Rate at different irradiances and culture conditions. Samples from the reactor were directly adjusted to the required culture conditions (temperature, $\mathrm{pH}$, dissolved oxygen) and subject to irradiances from 0 to $1500 \mu \mathrm{E} / \mathrm{m}^{2}$.s (Figueroa et al., 1997). Measurements were performed in parallel with photo-respirometry experiments thus allowing us to compare the performance of both methods in order to elucidate the influence of culture conditions on photosynthetic process performance.

\subsection{Biomass concentration and statistical analysis}

The microalgal biomass concentration was measured using dry weight measurements. For this, $50 \mathrm{~mL}$ samples were filtered through a Macherey-Nagel MN 85/90 glass fibre filter, and the filters containing the algae were dried in an oven at $80{ }^{\circ} \mathrm{C}$ for $24 \mathrm{~h}$. Data were analysed using the Statistica v.7 program. Data from the reactor were obtained from a total of 30 samples. Each measurement was performed in triplicate, both in situ and under laboratory conditions.

\section{Results and discussion}

\subsection{In situ measurements in the reactor}

The performance of whichever microalgae culture is a direct function of the irradiance to which the cells are exposed, in addition to how close the culture conditions are to those that are optimal for the selected microalgae, these being different for each strain. Light availability in outdoor reactors is a function of solar radiation on the reactor surface and reactor/culture parameters such as the light path, biomass concentration and biomass extinction coefficient. Therefore, to determine the average irradiance in outdoor cultures, the simplified equation proposed by Molina can be used (Eq. (1)), it providing the volumetric mean irradiance inside the reactor (Grima et al., 1994). Table 1 shows the most relevant irradiance values determined in the thin-layer reactor at different times. Because the entire solar collector is exposed to the same irradiance, the external irradiance on the reactor surface $\left(I_{o}\right)$ is a unique value at each point in time. The irradiance inside the culture was measured at the centre of the culture depth at different positions; a mean value of all the experimental values being obtained, which corresponds to the entire reactor ( $\left.\mathrm{I}_{\text {mean }}\right)$. Finally, because the culture's hydraulic residence time in the solar collector is really short, only

\section{Table 1}

Hourly variation in light availability and culture parameters in the thin-layer reactor. Mean values at the different positions measured.

\begin{tabular}{rrrrrrr}
\hline Time & Io, $\mu \mathrm{E} / \mathrm{m}^{2} \mathrm{~s}$ & $\mathrm{I}_{\text {mean }}, \mu \mathrm{E} / \mathrm{m}^{2} \cdot \mathrm{s}$ & $\mathrm{Iav}, \mu \mathrm{E} / \mathrm{m}^{2} \cdot \mathrm{s}$ & $\mathrm{T},{ }^{\circ} \mathrm{C}$ & $\mathrm{pH}$ & $\mathrm{DO}_{2}, \%$ Sat. \\
\hline $9: 00$ & 643 & 97 & 129 & 13.7 & 8.1 & 141 \\
$11: 00$ & 1620 & 90 & 324 & 19.7 & 8.3 & 195 \\
$13: 00$ & 902 & 101 & 180 & 23.2 & 8.6 & 197
\end{tabular}


$2 \mathrm{~min}$, the biomass concentration along the channel length would be considered constant as no biomass concentration gradients exist. Accordingly, a single average irradiance value in the reactor $\left(\mathrm{I}_{\mathrm{av}}\right)$ could be calculated at each point in time (Eq. (1)). The data show that the irradiance on the reactor surface varies over time from 643 to $1620 \mu \mathrm{E} /$ $\mathrm{m}^{2} \cdot \mathrm{s}$; the maximal value being obtained at $11: 00 \mathrm{~h}$ (as there was cloud at noon). Based on these values, the average irradiance to which the cells were exposed inside the reactor varied from 129 to $324 \mu \mathrm{E} / \mathrm{m}^{2}$.s for the same period of time. These values do not agree with those determined experimentally, which ranged from 90 to $101 \mu \mathrm{E} / \mathrm{m}^{2} \cdot \mathrm{s}$, although they are in the same order of magnitude. This is because it is difficult to adequately measure irradiance in thin-layer reactors - small variations in the sensor position and in the culture depth have a large effect on the final values. Consequently, utilizing average irradiance values instead of experimental measurements is recommended. In terms of the culture conditions inside the reactor, the mean values of temperature, $\mathrm{pH}$ and dissolved oxygen ranged from 13.7 to $23.2^{\circ} \mathrm{C}$, from 8.1 to 8.6 , and from 141 to $197 \%$ Sat., respectively; thus, they were in the range recommended for most microalgae strains (Table 1). It is important to note that, under these conditions, the biomass productivity measured was $11.7 \mathrm{~g} / \mathrm{m}^{2}$.day, with the reactor being operated in continuous mode at 0.3 day $^{-1}$ in winter time. This productivity was not high when compared to the $38 \mathrm{~g} / \mathrm{m}^{2}$.day previously reported in a $224 \mathrm{~m}^{2}$ unit (Doucha et al., 2009), or the $42 \mathrm{~g} / \mathrm{m}^{2}$.day reported when using centrate from an anaerobic digester as the nutrient source in a $32 \mathrm{~m}^{2}$ unit (Morales-Amaral et al., 2015a); although these values were obtained in summer time.

$I a v=\frac{I o}{K a \cdot C b \cdot p}(1-\exp (-K a \cdot C b \cdot p))$

Regarding the existence of gradients along the length of the reactor, the results show that the irradiance measurement at the different positions and times had no clear tendency, the standard deviation of the measurements being high; thus, these measurements were not confinable (Fig. 2A). This is due to the significant variation in the irradiance measurements caused by small changes in the culture depth along the reactor length, or because of the particular position where the light sensor was located. Therefore, it is recommended that the average irradiance values obtained from Eq. (1) are used. In contrast, the temperature showed a clear pattern, with no variation observed based on the position, yet it did increase with time (Fig. 2B). The culture temperature increases due to infrared radiation absorption from solar radiation - the larger the area exposed to the light (or solar radiation), the greater the increase in temperature. These figures show that, along the channel length, no temperature gradients occurred in thin-layer reactors, or they were not relevant; this is because of the short time to which the culture is exposed to solar radiation in the channel. However, during the day, the temperature increases because the energy input is greater than the output, which mainly results from evaporation. In a $220 \mathrm{~m}^{2}$ thin-layer reactor, a temperature increase from 20 to $35^{\circ} \mathrm{C}$ was previously reported during the daylight period (Doucha et al., 2009).

In the case of $\mathrm{pH}$, a similar trend was observed. The $\mathrm{pH}$ only slightly increased along the channel length but mean values over the day clearly increased (Fig. 2C). This signifies that the existence of $\mathrm{pH}$ gradients along the channel length can be disregarded as they are too small to significantly influence the performance of the cultures. This small $\mathrm{pH}$ increase along the channel length is explained by the on-demand injection of $\mathrm{CO}_{2}$ and the significant capacity of the carbonate-bicarbonate buffer in the culture medium, which compensates for the inorganic carbon consumption caused by photosynthesis along the channel length. However, the increase in $\mathrm{pH}$ over time, and moreover the existence of $\mathrm{pH}$ values above the set point of 8.0, indicates that overall $\mathrm{CO}_{2}$ injection was inadequate. According to these figures, the $\mathrm{CO}_{2}$ consumed by the microalgae was higher than the $\mathrm{CO}_{2}$ transference capacity, and although $\mathrm{pH}$ values were not too high, the mean hourly values increased from 8.1 to 8.6 (Table 1). The control of $\mathrm{pH}$ in thinlayer reactors has been already reported as a major factor determining the efficiency of these systems; and especially the efficiency of $\mathrm{CO}_{2}$ utilization (Lívanský and Doucha, 1996). The carbon supply is widely used to control and maintain $\mathrm{pH}$ close to the optimal value, which is important for ensuring optimal operating conditions inside the reactor; hence, the control of $\mathrm{pH}$ in thin-layer reactors must be carefully
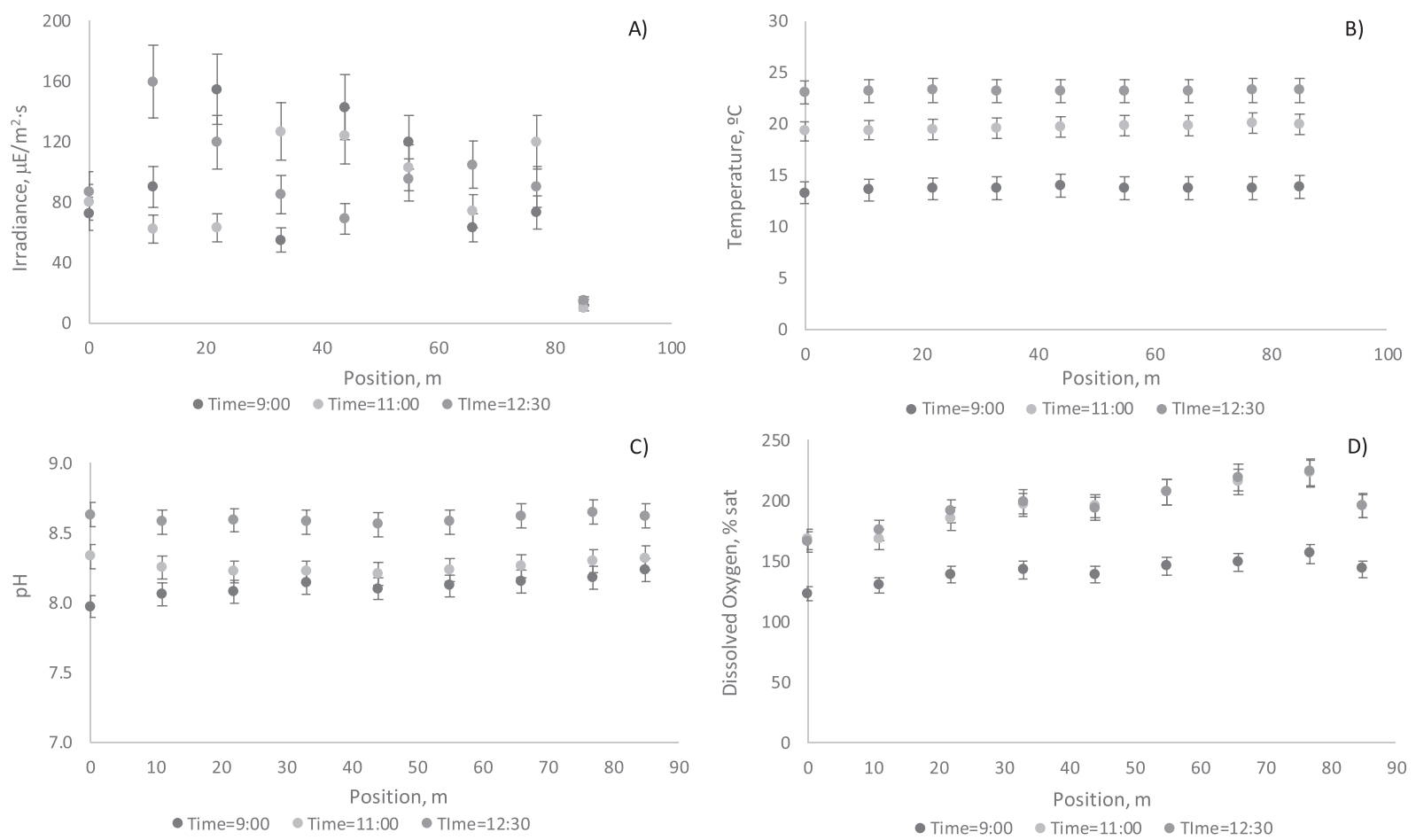

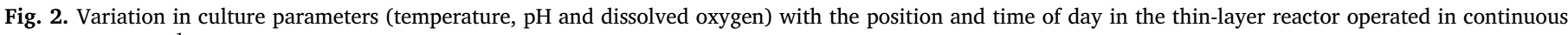
mode at 0.3 day $^{-1}$ at the IFAPA research centre. 


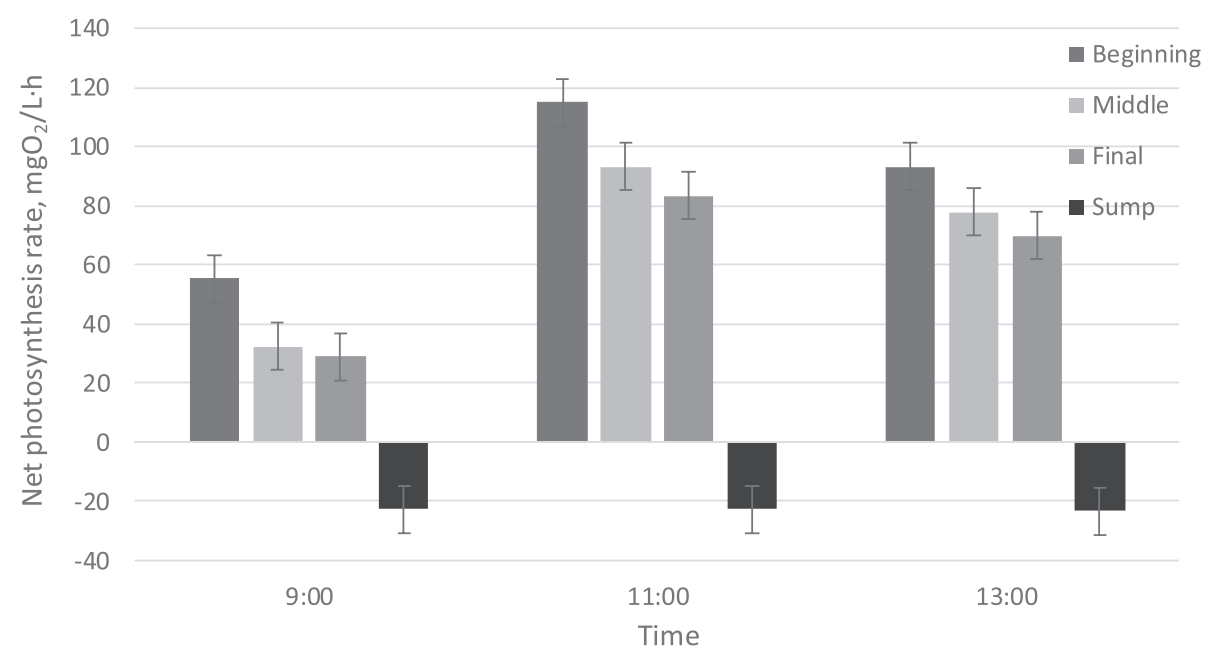

Fig. 3. In situ measurements of the photosynthesis rate at different positions in the thin-layer reactor.
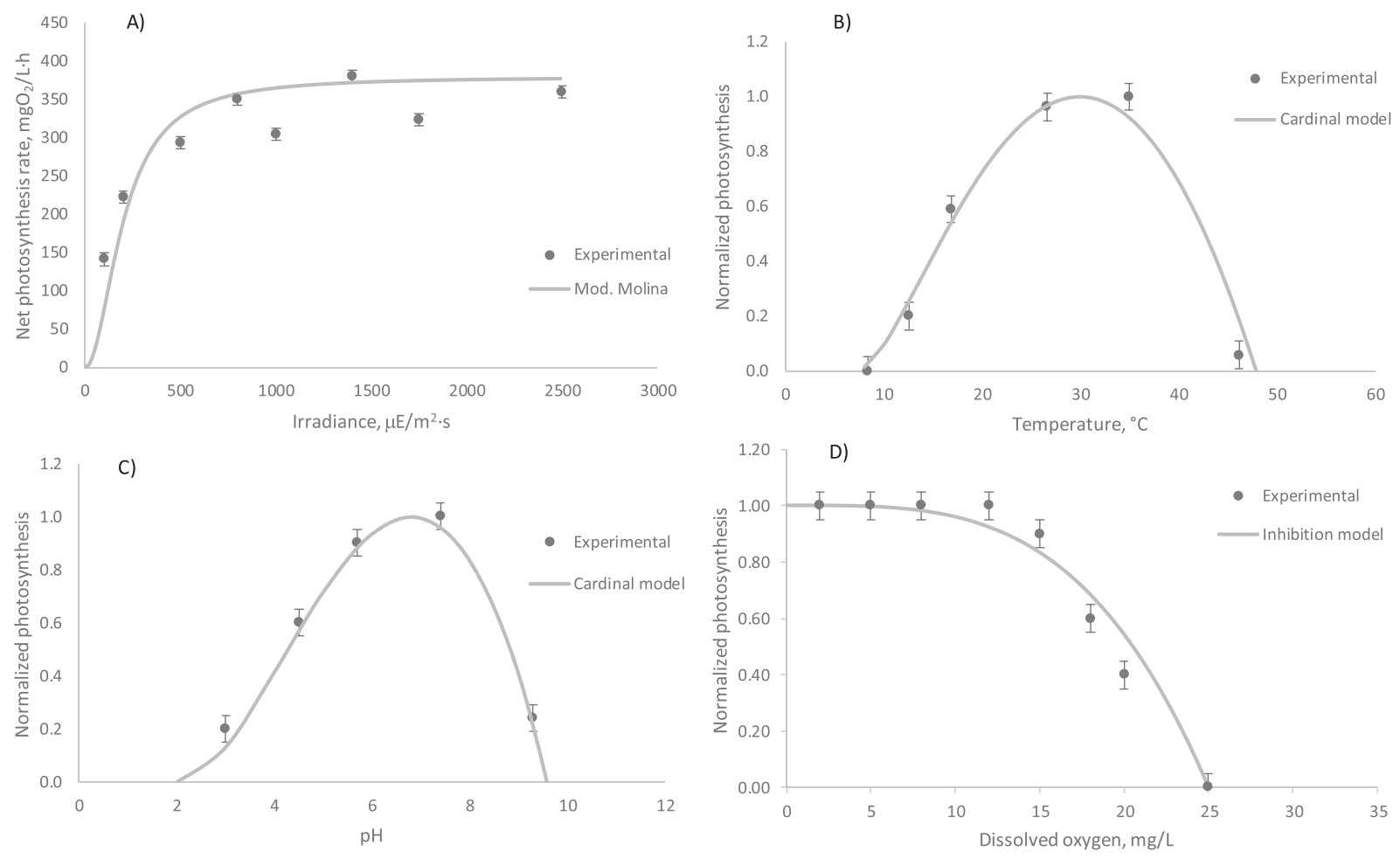

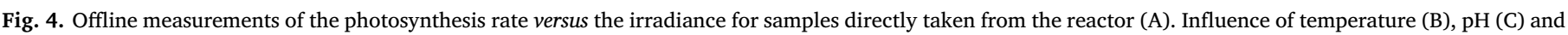

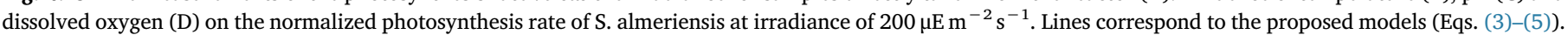

designed.

Regarding the dissolved oxygen concentration, a much larger variation was observed, both in terms of position and time. The dissolved oxygen concentration clearly increased with the position along the channel length due to oxygen accumulation produced by photosynthesis; the channels' desorption capacity not being enough to remove this oxygen (Fig. 2D). Through the day, the increase in average irradiance also enhanced the production of oxygen, and gradients of dissolved oxygen concentration increased. The mean values of dissolved oxygen concentration ranged from 141 to $197 \%$ Sat (Table 1) although values up to $225 \%$ Sat were experimentally determined at the end of the channel at 13:00 h, even on a cloudy day. Dissolved oxygen reduces the performance of microalgae cultures if concentration values exceed $250 \%$ Sat.; this is because the photosynthesis rate reduces exponentially above this value (Fernández et al., 2012; Pawlowski et al., 2014). The existence of excessive dissolved oxygen in thin-layer reactors has already been reported, with values up to $23 \mathrm{mg} / \mathrm{L}$ being measured (Doucha and Lívanský, 2006; Lívanský and Doucha, 1996).

To determine the influence of these experimental conditions on culture performance, in situ measurements of net photosynthesis rates at different reactor positions were carried out. These were taken at the beginning, middle and end of the channel, as well as in the sump (Fig. 3). The data show that the net photosynthesis rate varies based on the position in the reactor and the time (as a result of changes in solar radiation availability over time). In terms of the position, the sump is shown to be a dark volume, with the cells respiring in this section; here, values as low as $-23 \mathrm{mgO}_{2} / \mathrm{L} \cdot \mathrm{h}$ were measured. Conversely, in the channel, a greater photosynthesis rate is always measured after the bubble column, where the culture is adjusted to the optimal conditions; thus, at the beginning of the solar collector, values from 55 to 

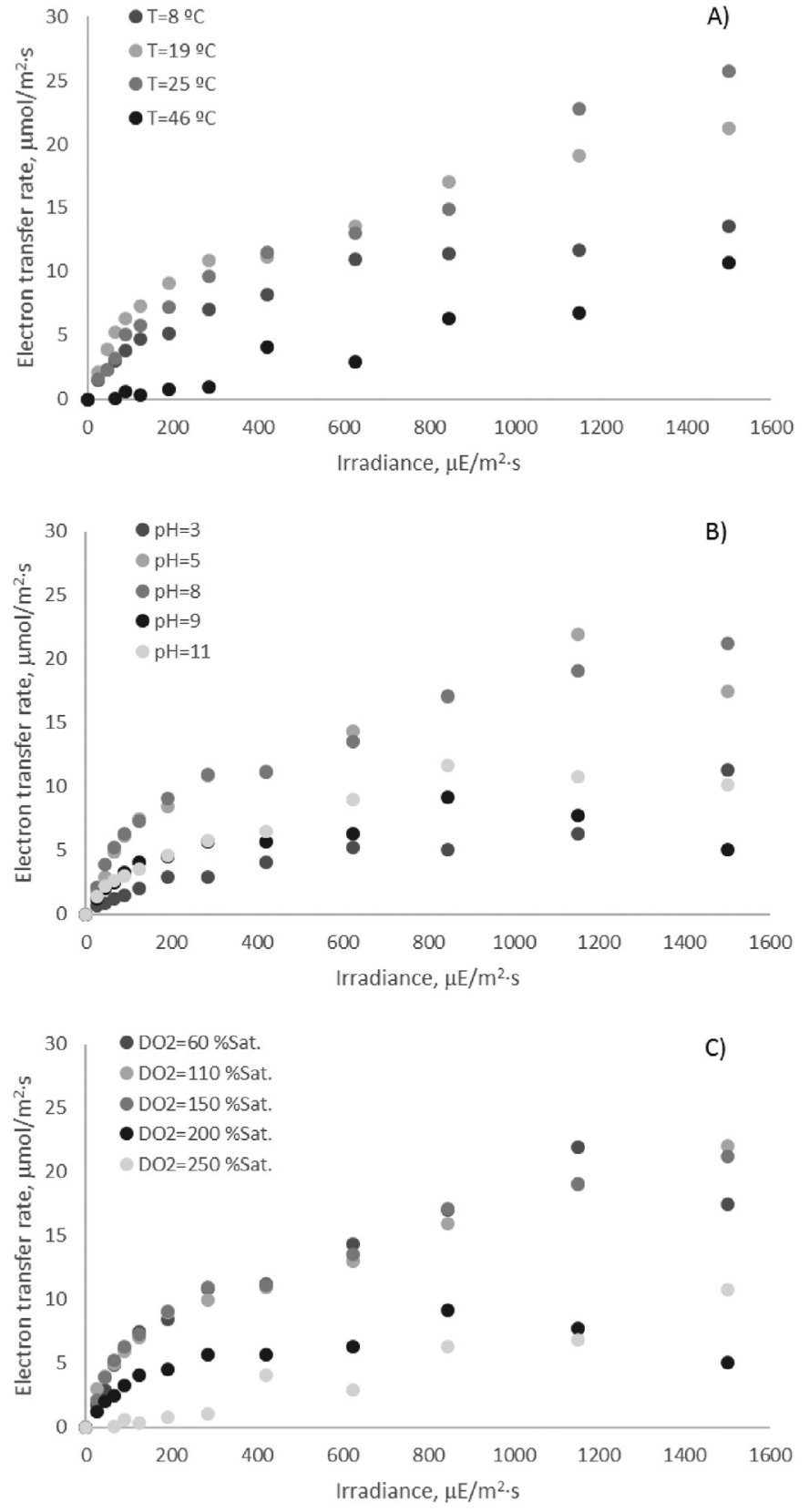

Fig. 5. Influence of temperature (A), $\mathrm{pH}(\mathrm{B})$ and dissolved oxygen (C) on the electron transfer rate of Scenedesmus almeriensis cells. Data from Chlorophyllfluorescence measurements.

$115 \mathrm{mgO}_{2} / \mathrm{L}$.h were measured. In the middle of the channel, the net photosynthesis rate reduces, reducing yet further at the end of the channel; this confirms that the modified culture parameters along the channel length create adverse conditions for the photosynthetic process. The values at the end of the channel ranged from 29 to $83 \mathrm{mgO}_{2} /$ $\mathrm{L} \cdot \mathrm{h}$. The hourly variation in the photosynthesis rate agrees with the variation in solar irradiance measured on the reactor surface, and the average irradiance calculated inside the culture; behaviour that we expected to see.

\subsection{Offline measurements in the laboratory}

To confirm the influence of changing culture conditions on the cell performance offline, measurements were performed in the laboratory that simulated the culture conditions prevailing outdoors. For this, the net photosynthesis rate and chlorophyll-fluorescence methods were used. Regarding the net photosynthesis rate, experiments were carried out that modified the irradiance to which the cells were exposed, showing the typical light curve response of the photosynthesis rate (Fig. 4A). These measurements were performed under the optimal conditions of temperature $\left(25^{\circ} \mathrm{C}\right), \mathrm{pH}(8.0)$ and dissolved oxygen ( $9 \mathrm{mg} / \mathrm{L}=100 \%$ Sat.). By fitting the experimental values to the hyperbolic model proposed by Molina et al., (Eq. (2)) (Molina-Grima et al., 1994), the characteristic parameter values of the model were obtained $\left(\mathrm{PO}_{2, \text { max }}=380 \mathrm{mgO}_{2} / \mathrm{L} \cdot \mathrm{h}, \mathrm{I}_{\mathrm{k}}=200 \mu \mathrm{E} / \mathrm{m}^{2} \cdot \mathrm{s}, \mathrm{n}=2\right)$. Therefore, for the entire solar radiation range, we can simulate the curve representing the model. The data show that the model accurately represents the experimental figures; moreover, one can observe that a maximal photosynthesis rate of $350 \mathrm{mgO}_{2} / \mathrm{L} \cdot \mathrm{h}$ is achieved at average irradiances of $500 \mu \mathrm{E} / \mathrm{m}^{2} \cdot \mathrm{s}$; above this value the cultures become saturated.

$P O_{2}=\frac{P O_{2, \max } \cdot I_{a v}{ }^{n}}{I_{k}{ }^{n}+I_{a v}{ }^{n}}$

To analyse the net photosynthesis rate response to changes in culture parameters (temperature, $\mathrm{pH}$ and dissolved oxygen), normalized values were used. To do this, net photosynthesis rate measurements were taken at different temperature, $\mathrm{pH}$ and dissolved oxygen values; for each data set, the experimental photosynthesis rate values were divided by the maximal value to help understand and compare the final results. Regarding the temperature, the results show that temperatures below $26^{\circ} \mathrm{C}$, or above $34^{\circ} \mathrm{C}$, significantly reduce the culture performance; at temperatures of $12{ }^{\circ} \mathrm{C}$ and $46^{\circ} \mathrm{C}$, the photosynthesis rate becomes almost negligible (Fig. 4B). In the case of $\mathrm{pH}$, a similar trend was observed - the net photosynthesis rate is close to the maximal value from 5.7 to 8.0; outside this range it markedly reduces, nearing zero at $\mathrm{pH}$ values of 3 and 10 (Fig. 4C). Regarding the influence of the dissolved oxygen concentration, a different trend was observed - the photosynthesis rate remaining constant at dissolved oxygen concentrations below $15 \mathrm{mg} / \mathrm{L}$ (135\%Sat.) whereas above $20 \mathrm{mg} / \mathrm{L}$ (180\% Sat.), it nears zero (Fig. 4D). These results confirm previous studies concerning the effect of culture conditions on Scenedesmus almeriensis, which showed the optimal $\mathrm{pH}$ to be in the range of 7.0 to 9.0, and the maximal photosynthesis activity to be at a temperature of $35^{\circ} \mathrm{C}$, reducing dramatically at temperatures above this (Costache et al., 2013).

The experimental figures can be fitted to the different models to modelize the influence of culture conditions on cell performance. In the case of temperature and $\mathrm{pH}$, using the cardinal model is recommended (Bernard and Rémond, 2012; Ippoliti et al., 2016a) whereas for dissolved oxygen, using models that consider the inhibition by product is advised (Costache et al., 2013; Ippoliti et al., 2016a).

$$
\begin{aligned}
& R O 2(T)=\frac{(T-T \max )(T-T \text { min }) 2}{(\text { Topt }- \text { Tmin })(((T o p t-T \text { min })(T-T o p t))} \\
& -((\text { Topt }- \text { Tmax })(\text { Topt }+ \text { Tmin }-2 T))) \\
& R O 2(p H)=\frac{(p H-p H \max )(p H-p H \text { min }) 2}{(p H o p t-p H \text { min })(((p H o p t-p H \text { min })(p H-p H o p t))} \\
& -((p H o p t-p H \max )(p H o p t+p H \min -2 p H))) \\
& \operatorname{RO} 2\left(D_{2}\right)=1-\left(\frac{D O_{2}}{D O_{2, \max }}\right)^{m}
\end{aligned}
$$

By fitting the experimental values to these equations, the models' characteristic parameter values were obtained. In terms of the temperature, the maximum and minimum tolerable temperatures were 48 and $7{ }^{\circ} \mathrm{C}$, respectively, while the optimal temperature was $30^{\circ} \mathrm{C}$. For $\mathrm{pH}$, the maximum and minimum tolerable values were 9.6 and 2.0 , respectively, whereas the optimal $\mathrm{pH}$ was 6.8. In the case of the dissolved oxygen concentration, the maximum dissolved oxygen concentration tolerated by the culture was $25 \mathrm{mg} / \mathrm{L}(225 \%$ Sat.), the proposed model's form parameter having a value of 3.5 .

These results are comparable to those obtained when evaluating the 

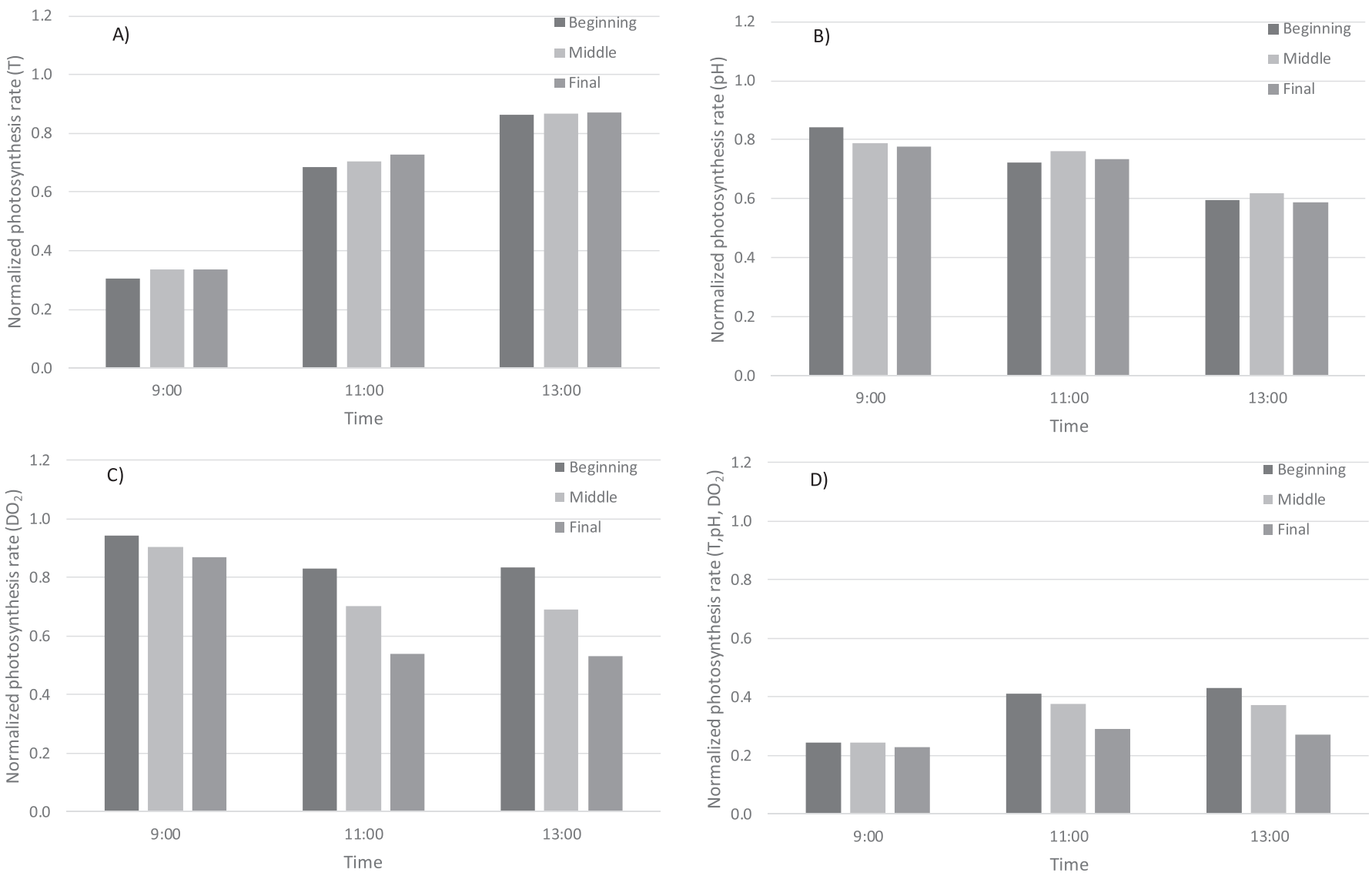

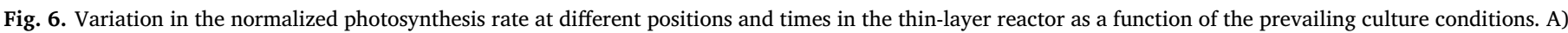

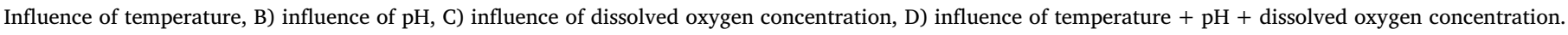

electron transfer rate of the cells in the reactor by taking chlorophyll fluorescence measurements. The data in Fig. 5 show that temperature has a negative effect on the electron transfer rate at values of 8 and $46^{\circ} \mathrm{C}$, with no photo inhibition being observed up to $1500 \mu \mathrm{E} / \mathrm{m}^{2} \cdot \mathrm{s}$. In the case of $\mathrm{pH}$, an adverse effect was observed at values below $\mathrm{pH} 5$ and above $\mathrm{pH}$ 8; the lowest electron transfer rate being measured at $\mathrm{pH} 3$. Finally, regarding the influence of dissolved oxygen, a similar trend was observed to that of the photosynthesis rate - the electron transfer rate showed a similar trend to that of irradiance at dissolved oxygen concentrations below $150 \%$ Sat.; above this value it significantly reduced. Although a relationship between the electron transfer rate and the oxygen production rate can be developed, it is preferable to use the previous models of the photosynthesis rate as a function of the culture conditions to estimate Scenedesmus almeriensis cell behaviour under different conditions. The utilization of Chlorophyll-fluorescence measurements to identify adverse culture conditions in thin-layer reactors has already been reported; they are also recommended as a rapid tool for optimizing water depth in these types of reactors (Jerez et al., 2014, 2016).

\subsection{Evaluation of productivity losses in the thin-layer reactor}

The results reported here demonstrate that inadequate culture conditions occur in thin-layer reactors, both along the channel length and over time. Experimental photosynthesis rate measurements confirm that these inadequate culture conditions reduce the net photosynthesis rate of the Scenedesmus almeriensis produced in this type of reactor. Moreover, Chlorophyll-fluorescence measurements confirm this behaviour, allowing us to identify the value limits for the most relevant culture conditions such as temperature, $\mathrm{pH}$ and dissolved oxygen. To quantify the loss in productivity caused by inadequate culture conditions along the channel length and over time, the normalized photosynthesis rates for each of the main variables have been calculated using the obtained models (Fig. 6). The results show that in the early morning, low temperature is the main factor inhibiting Scenedesmus almeriensis cell performance, with normalized photosynthesis rate values below 0.4 being measured at 9:00 h, although these increase to 0.87 at noon (Fig. 6A). Conversely, the $\mathrm{pH}$ level is adequate in the early morning when the $\mathrm{CO}_{2}$ demand is low, the normalized photosynthesis rate being 0.84 ; however, this drops to 0.59 at noon when the $\mathrm{CO}_{2}$ supply is insufficient to cover the culture demand (Fig. 6B). The dissolved oxygen concentration is the variable showing the greatest variation depending on the position in the channel, with the normalized photosynthesis rate decreasing along the reactor length from 0.94 to 0.87 in the early morning, and from 0.84 to 0.53 at noon (Fig. $6 \mathrm{C}$ ). When multiplying all these factors together, the overall normalized photosynthesis rate can be calculated. The results show that, in the early morning, the normalized photosynthesis rate remains below 0.24 wherever the position along the channel, increasing up to maximal values of 0.43 at noon at the beginning of the channel but dropping to 0.27 at the end of the channel at this time (Fig. 6D). This behaviour has already been reported in tubular photobioreactors producing T-ISO, with similar normalized photosynthesis rates (Ippoliti et al., 2016b). It has therefore been demonstrated that this methodology is a useful tool for optimizing the design and operation of whichever type of large-scale reactor.

When considering all these factors, the average normalized photosynthesis rate was 0.32 , indicating that one could increase the net photosynthesis rate to $68 \%$ if the culture conditions inside the reactor were improved. In terms of the net photosynthesis rate, this signifies that the mean measured value of $62 \mathrm{mgO}_{2} / \mathrm{L}$ h could be increased to $185 \mathrm{mgO}_{2} / \mathrm{L} \cdot \mathrm{h}$ under optimal culture conditions. Considering the basic 
photosynthesis equation, this means that the maximal achievable productivity is close to $32 \mathrm{~g} / \mathrm{m}^{2}$ day, even though the estimated productivity, according to the developed model, was $10.5 \mathrm{~g} / \mathrm{m}^{2}$.day; the actual value being measured on the basis of the biomass dry weight and a dilution rate of $11.7 \mathrm{~g} / \mathrm{m}^{2}$.day. Accordingly, it has been demonstrated that thin-layer reactors still need to be better characterized and evaluated to achieve robust systems that can perform adequately at the industrial scale. Moreover, the modifications required to achieve full control of control conditions allowing to optimize the biomass productivity must be also analysed from the sustainability point of view, the sustainability of microalgae based processes being recently discussed (Barsanti and Gualtieri, 2018).

\section{Conclusions and future prospects}

Inadequate culture conditions occur in thin-layer reactors, both with the position along the reactor and over time. Temperature mainly varies along the day, no gradients with the position being observed, whereas large variation $\mathrm{f}$ of $\mathrm{pH}$ and especially of dissolved oxygen concentration occurs both with time and position. The inadequacy of culture conditions was demonstrated to reduce the performance of Scenedesmus almeriensis cultures. The methodology used here is of great use for improving the design and performance of whatever reactor. It has been demonstrated that the net photosynthesis rate can be multiplied three-fold if optimized thin-layer reactors are used.

\section{Conflict of interest statement}

The authors declare that there are any potential financial or other interests that could be perceived to influence the outcomes of the research.

\section{Acknowledgements}

Thanks to the young students who also participated in this work: Rosalía Acien, Paula Blanco, María Casado, María José Ferre, Claudia López, Isabel López, Elena López y Marta Velar. This study was part of the Science IES programme for young students, and it was supported by the Ministry of Economy and Competitiveness (DPI2014-55932-C2-1-R, DPI2017-84259-C2-1-R) and (PURASOL, CTQ2017-84006-C3), along with the European Union's Horizon 2020 Research and Innovation Program under Grant Agreement No. 727874 SABANA. We are most grateful for the practical assistance given by the staff of the "IFAPA" Experimental Station.

\section{References}

Acién, F.G., Molina, E., Reis, A., Torzillo, G., Zittelli, G.C., Sepúlveda, C., Masojídek, J., 2017. Photobioreactors for the production of microalgae. In: Microalgae-Based Biofuels and Bioproducts: From Feedstock Cultivation to End-Products.

Barsanti, L., Gualtieri, P., 2018. Is exploitation of microalgae economically and energetically sustainable? Algal Res. 31, 107-115.

Benemann, J., 2013. Microalgae for biofuels and animal feeds. Energies 6, 5869-5886. Bernard, O., Rémond, B., 2012. Validation of a simple model accounting for light and temperature effect on microalgal growth. Bioresour. Technol. 123, 520-527.

Camacho Rubio, F., Acien Fernandez, F.G., Sáchez Pérez, J.A., García Camacho, F., Molina Grima, E., 1999. Prediction of dissolved oxygen and carbon dioxide concentration profiles in tubular photobioreactors for microalgal culture. Biotechnol. Bioeng. 62 (1), 71-86.

Costache, T.A.A., Fernández, F.G.A., Acien, F.G., Morales, M.M., Fernández-Sevilla, J.M., Stamatin, I., Molina, E., 2013. Comprehensive model of microalgae photosynthesis rate as a function of culture conditions in photobioreactors. Appl. Microbiol. Biotechnol. 97, 7627-7637.

de Godos, I., Mendoza, J.L., Acién, F.G., Molina, E., Banks, C.J., Heaven, S., Rogalla, F., 2014. Evaluation of carbon dioxide mass transfer in raceway reactors for microalgae culture using flue gases. Bioresour. Technol. 153, 307-314.

Doucha, J., Lívanský, K., 2006. Productivity, CO2/O2 exchange and hydraulics in outdoor open high density microalgal (Chlorella sp.) photobioreactors operated in a Middle and Southern European climate. 18, 811-826.

Doucha, J., Lívanský, K., Lívanský, K., 2009. Outdoor open thin-layer microalgal photobioreactor: potential productivity. J. Appl. Phycol. 21, 111-117.

Fernández, I., Acién, F.G., Fernández, J.M., Guzmán, J.L., Magán, J.J., Berenguel, M., 2012. Dynamic model of microalgal production in tubular photobioreactors. Bioresour. Technol. 126, 172-181.

Figueroa, F.L., Jiménez, C., Lubián, L.M., Montero, O., Lebert, M., Häder, D.-P., 1997. Effects of high irradiance and temperature on photosynthesis and photoinhibition in Nannochloropsis gaditana Lubián (Eustigmatophyceae). J. Plant Physiol. 151, 6-15.

Gao, X., Kong, B., Vigil, R.D., 2018. Simulation of algal photobioreactors: recent developments and challenges. Biotechnol. Lett. 40, 1311-1327.

Grima, E.M., Camacho, F.G., Pérez, J.A.S., Sevilla, J.M.F., Fernández, F.G.A., Gómez, A.C., 1994. A mathematical model of microalgal growth in light-limited chemostat culture. J. Chem. Technol. Biotechnol. 61, 167-173.

Grobbelaar, J.U., 2010. Microalgal Biomass Production: Challenges and Realities.

Ippoliti, D., Gómez, C., Morales-Amaral, M.M., Pistocchi, R., Fernández-Sevilla, J.M.M., Acién, F.G.G., 2016a. Modeling of photosynthesis and respiration rate for Isochrysis galbana (T-Iso) and its influence on the production of this strain. Bioresour. Technol. 203, 71-79.

Ippoliti, D., González, A., Martín, I., Sevilla, J.M.F., Pistocchi, R., Acién, F.G., 2016b. Outdoor production of Tisochrysis lutea in pilot-scale tubular photobioreactors. J. Appl. Phycol. 28, 3159-3166.

Jerez, C.G., Navarro, E., Malpartida, I., Rico, R.M., Masojídek, J., Abdala, R., Figueroa, F.L., 2014. Hydrodynamics and Photosynthesis Performance of Chlorella fusca (Chlorophyta) Grown in a Thin-Layer Cascade (TLC) System. vol. 22. pp. 111-122.

Jerez, C.G., Malapascua, J.R., Sergejevová, M., Masojídek, J., Figueroa, F.L. 2016. Chlorella Fusca (Chlorophyta) Grown in Thin-Layer Cascades: Estimation of Biomass Productivity by In-Vivo Chlorophyll a Fluorescence Monitoring. vol. 17. pp. 21-30.

Lívanský, K., Doucha, J., 1996. CO2 and O2 gas exchange in outdoor thin-layer high density microalgal cultures. J. Appl. Phycol. 8, 353-358.

Lívanský, K., Doucha, J., Hu, H., Li, Y., 2006. CO2 partial pressure - pH relationships in the medium and relevance to $\mathrm{CO} 2$ mass balance in outdoor open thin-layer Arthrospira (Spirulina) cultures. Arch. fur Hydrobiol. 165, 365-381.

Malapascua, J.R.F., Jerez, C.G., Sergejevová, M., Figueroa, F.L., Masojídek, J., 2014. Photosynthesis Monitoring to Optimize Growth of Microalgal Mass Cultures: Application of Chlorophyll Fluorescence Techniques. vol. 22. pp. 123-140.

Masojídek, J., Prášil, O., 2010. The Development of Microalgal Biotechnology in the Czech Republic. pp. 1307-1317.

Masojídek, J., Malapascua, J.R., Kopecký, J., Sergejevová, M., 2015. Thin-layer systems for mass cultivation of microalgae: Flat panels and sloping cascades. In: Algal Biorefineries: Volume 2: Products and Refinery Design. Springer International Publishing, Cham, pp. 237-261.

Mendoza, J.L., Granados, M.R., de Godos, I., Acién, F.G., Molina, E., Heaven, S., Banks, C.J., 2013. Oxygen transfer and evolution in microalgal culture in open raceways. Bioresour. Technol. 137, 188-195.

Molina-Grima, E., García-Camacho, F., Sánchez-Pérez, J.A., Fernández-Sevilla, J.M., Acién, F.G., Contreras-Gómez, A., 1994. A mathematical model of microalgal growth in light-limited chemostat culture. J. Chem. Technol. Biotechnol. 61, 167-173.

Morales-Amaral, M. del M., Gómez-Serrano, C., Acién, F.G., Fernández-Sevilla, J.M., Molina-Grima, E., 2015a. Outdoor production of Scenedesmus sp. in thin-layer and raceway reactors using centrate from anaerobic digestion as the sole nutrient source. Algal Res. 12, 99-108.

Morales-Amaral, M. del M., Gómez-Serrano, C., Acién, F.G., Fernández-Sevilla, J.M., Molina-Grima, E., 2015b. Outdoor production of Scenedesmus sp. in thin-layer and raceway reactors using centrate from anaerobic digestion as the sole nutrient source. Algal Res. 12, 99-108.

Pawlowski, A., Mendoza, J.L., Guzmán, J.L., Berenguel, M., Acién, F.G., Dormido, S., 2014. Effective utilization of flue gases in raceway reactor with event-based $\mathrm{pH}$ control for microalgae culture. Bioresour. Technol. 170, 1-9. 